\title{
A NOTE ON THE EARLY STAGES OF LEPISELAGA CRASSIPES FAB. (DIPT., TABANID $Æ$ )
}

\author{
By G. B. FAIRCHILd, \\ Junior Entomologist, \\ Gorgas Memorial Laboratory, \\ Panamá, R. de $\mathrm{P}$.
}

Information about the early stages of Neotropical Tabanidæ may almost be said to be non-existent. Bodkin and Cleare (1916) have given a brief description of the larvæ and a figure of the pupal aster of Tabanus desertus Wlk. Ad. Lutz (1920, 1922 and 1928) has mentioned raising a few species from larvæ, and has described a method of rearing using agar as a medium (1920), but so far as I am aware these are the only descriptions or figures of larvæ or pupæ of any of the many Neotropical forms that have ever been published.

Inasmuch as the classification of the Tabanidæ, so far based entirely on adult characters, is in a very unsatisfactory condition, I feel that any information about the structure and habits of the early stages is very important, and may throw some much needed light on the relationships of the many forms.

The present species has apparently been reared more often than any other, and has been mentioned several times in the literature. Ad. Lutz (1928) raised a single adult from a larva collected in plants of Pistia stratiotes, the water lettuce, in Venezuela, and gives an unrecognizable figure of the pupal shell. Dunn (1934) also raised the adults from larvæ taken in the same habitat in Panama, but says nothing about the appearance of either larva or pupa.

During the early months of 1929 , while searching for mosquito larvæ in the floating vegetation along the Chagres 
River between Gamboa and Madden Dam in the Panama Canal Zone, I occasionally dipped up small pupal shells of what I suspected might be Lepiselaga. Comparison of these with a specimen in our collection from which Dunn had bred Lepiselaga confirmed my suspicion.

Although, for reasons which are not known, Pistia has become very scarce throughout the Canal Zone this year, I have taken the adult Lepiselaga in fair numbers throughout the year. I suspect, therefore, that it is not entirely dependent on this plant, but may be associated with other types of aquatic vegetation as well. In April 1939, while collecting in a small slough near the laboratory's station at Juan Mina on the Chagres River, I secured two small greenish larvæ from the matted floating vegetation near the shore line. This vegetation consisted of floating debris, mats of filamentous algæ, the water-fern Salvinia, and a few small plants of Pistia not over 1.5 inches in diameter. The larvæ were associated with a rather rich fauna of aquatic insects, including larvæ of Odonata, Ephemerida and Stratiomyiidx, and numerous species of aquatic Coleoptera and Hemiptera. At the same time I also took two pupal shells. Later, in mid-May of the same year, I collected two more larvæ of Lepiselaga in a grassy swamp near Gamboa. They were in the floating scum on the water, and no Pistia was present in the swamp.

The first two larvæ were kept in the laboratory in shell vials measuring $3 \times 1$ inches, into which about 1 inch of $2 \%$ agar had been poured. This medium remains more or less transparent for one or two weeks, when the larvæ may be removed to a new tube if it is desired to keep them under close observation. Inoculation of the medium with some unicellular green alga seems to keep the medium from becoming putrid for a longer time, but the dark green color interferes with observation. To provide a suitable place for pupation, paper towelling is cut into strips 1.5 inches wide and 3 or 4 inches long, rolled into a cylinder the size of a lead pencil, moistened and inserted upright into the agar. The tubes are stoppered tightly with cotton, which must not touch the roll of paper, or it will suck all excess moisture from the paper and agar. The larvæ may be fed upon aquatic earthworms, Chironomid larvæ or other small soft- 
bodied forms, but I have found the most satisfactory food to be ordinary earthworms. A culture of these may be kept in the laboratory for long periods, and one fair-sized worm cut in pieces will feed ten or a dozen larvæ.

After about 3 weeks in the laboratory, during which they both fed several times, one of these larvæ pupated, yielding a pupa which resembled the empty pupal shells I had previously found. The other was hastily preserved for study. I was obliged to leave the laboratory for five days after this, and when I returned, found that a male Lepiselaga had emerged in my absence, so that the pupal period is not more than a week and probably 4 or 5 days.

The full-grown larva is about $15 \mathrm{~mm}$. long by $3-3.5 \mathrm{~mm}$. wide at the widest part in the region of the 5th or 6th segment, circular in cross-section, or sometimes slightly flattened ventrally. In color it is a light yellowish green with a complicated dorsal pattern of dark grey spots and blotches on the second to tenth segments. Laterally there are two short parallel longitudinal dark lines of spots; below there is a dark spot on each of the second to 10th segments. The ventral surface is unmarked, as are the first and last segments. Both the head and siphon are unusually slender, and the anterior part of the body has great powers of extension, so that when extended in crawling the head and first two segments may make up $3 / 4$ of the total length. The locomotory protuberances include a narrow transverse dorsal pair, a rounded lateral protuberance on each side, and an oval ventral pair. Thus each segment from the 6 th to the 10th inclusive bears 6 protuberances. The 5 th segment lacks the ventral pair, and the dorsal pair are narrowed. These protuberances are extensile to some extent and bear dense short hairs. There are also a few long hairs in the head and anal regions, and at least a lateral pair on each segment, which are difficult to see. The anal region is less swollen than in other Tabanid larvæ I have seen, and does not appear to be used so much in locomotion. The apical part of the siphon is rather heavily chitinized and longitudinally striated, and bears near its apex four groups of three hairs each. The opening at the apex is a vertical slit fringed with minute hairs. In this slit, and lying between the ends of the two big tracheal trunks, is a heavily chitinized spear- 
like structure which seems to be capable of considerable extrusion and retraction. Hart (1895) mentions this structure as being present in all the Tabanid larvæ he examined, but noted that it was retractile, so that in many specimens it was not visible. He gives a figure of it in lateral view for Tabanus nigrescers. Stone (1930) also mentions this structure and uses it in his key, it being found in some species of Chrysops and Tabanus but not in others. Such a structure would seem quite well adapted to piercing the air spaces in the roots and leaves of such aquatic plants as Pistia and Piaropus, while allowing the larva to secure air from the water surface when such plants are not available. In any case, the larvæ live quite well under artificial conditions, apparently not needing aquatic vegetation from which to secure air.

The pupa is $10-14 \mathrm{~mm}$. long, the abdomen relatively short, for the head and thoracic region are only slightly less than half the total length of the pupa. The head-capsule is smooth and rounded, lacking the bosses and rugosities often found in other species of the family. The thoracic spiracles are produced into relatively long conical trumpets, which are directed sidewise with their openings on the ventral side of the apex. These elongated thoracic trumpets have been found in only one other Tabanid, so far as I am aware. King (1926) records similar structures for Tabanus fasciatus niloticus Aust., a species which he found breeding in Pistia on the Nile. The 1st. to 4th. free abdominal segments bear long spines where the spiracles should occur. These at first sight appear to be breathing-tubes, but I cannot find that they are open at the apex. Each abdominal segment in addition bears a row of fine spines of variable length near its posterior margin, which are longer on the dorsal side. The female aster is shown in Fig. 5. The male aster is narrower, the lateral spines are relatively longer, and the ventral region of the last segment is considerably inflated. In color the pupa is light leaf green, becoming nearly black before emergence, when the colors of the adult can be clearly seen through the integument. 


\section{EXPLANATION OF PLATE II.}

Fig. 1. Dorsal view of full grown larva of Lepiselaga crassipes, showing distribution of locomotory protuberances. Color markings omitted.

Fig. 2. Dorsal view of 7 th segment, showing color pattern.

Fig. 3. Dorsal view of Siphon. a. tracheal trunks. b. apical slit. c. siphonal spear.

Fig. 4. Lateral view of ô pupa.

Fig. 5. Terminal view of last segment and aster of $q$ pupa.

\section{REFERENCES.}

1895 Hart, C. A. On the Entomology of the Illinois River and Adjacent Waters. First Paper. Bull. Illinois State Lab. Nat. Hist. IV, Article Vi. p. 222, pl. XI, Fig. 48. Urbana, Illinois. 1895.

1916 Bodkin, G. E. and Cleare, L. D., Jr. Notes on some animal parasites in British Guiana. Bull. Ent. Res., VII, p. 184, Fig. 1, 1916.

1920 Ad. Lutz, Obervação de vermes e larvas terrestres ou limicolas em ambiente transparente. Folha Medica, Anno. 1, No. 3, March 1920 (Separate).

1922 Ad. Lutz, Zoologia Medica. Folha Medica, p. 89. (Separate).

1926 King, H. H. A note on the bionomics of Tabanus fasciatus niloticus Aust. Bull. Ent. Res., I6, p. 359, March 1926.

1928 Ad. Lutz, Estudios de Zoologia y Parasitologia Venezolanos, Rio de Janeiro, pp. 59-60, pl. 3, fig. 7, Dec., 1938.

1930 Stone, Alan. The Bionomics of some Tabanidae (Diptera) Ann. Ent. Soc. Amer. XXIII, 2, pp. 261-304, Figs. 1-12, June 1930.

1934 Dunn, L. H. Notes on the water lettuce, Pistia stratiotes, as a nursery of insect life. Ecology, XV, No. 3, pp. 329-333, July 1934. 

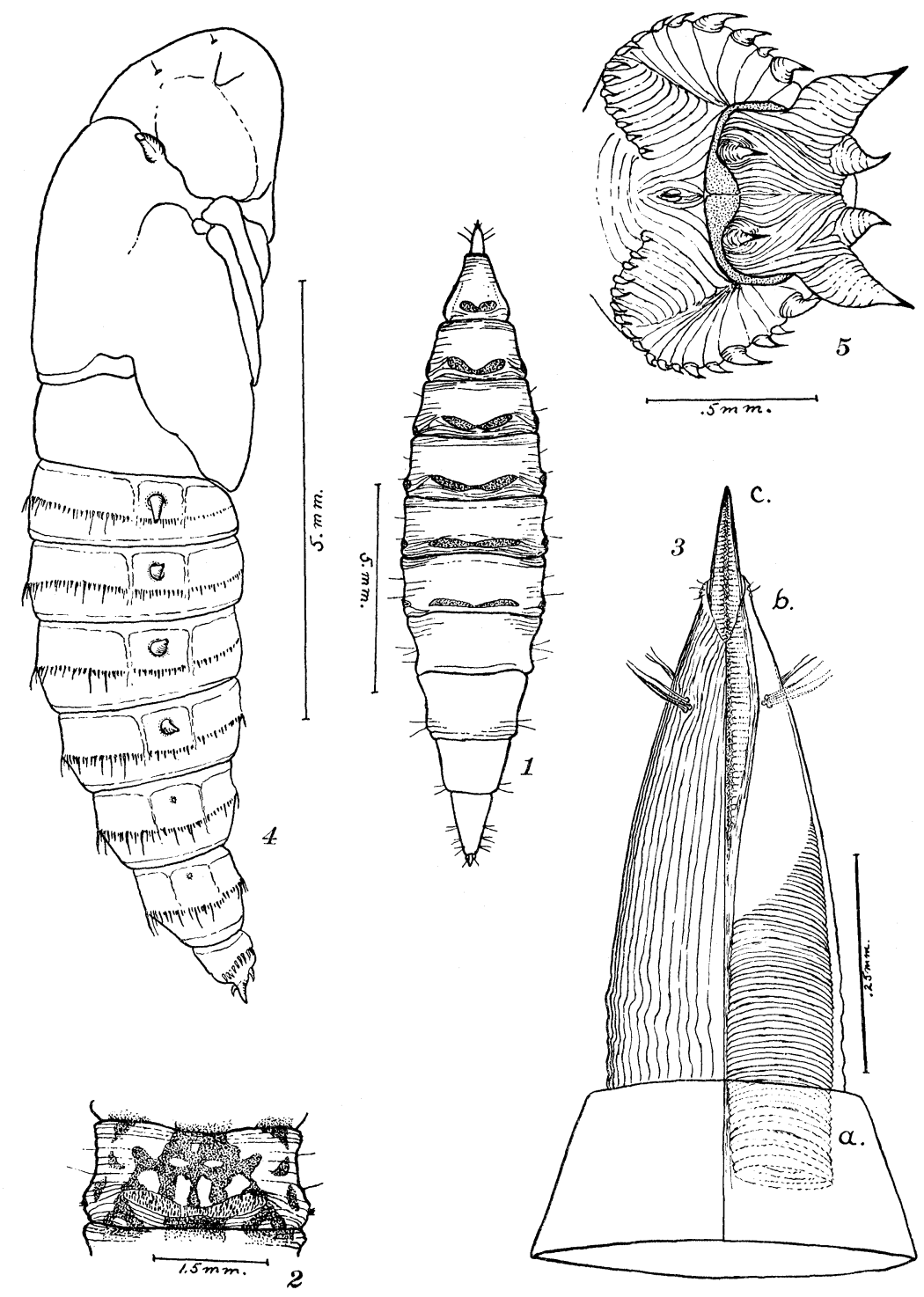

Fairchild - Lepiselaga crassipes 

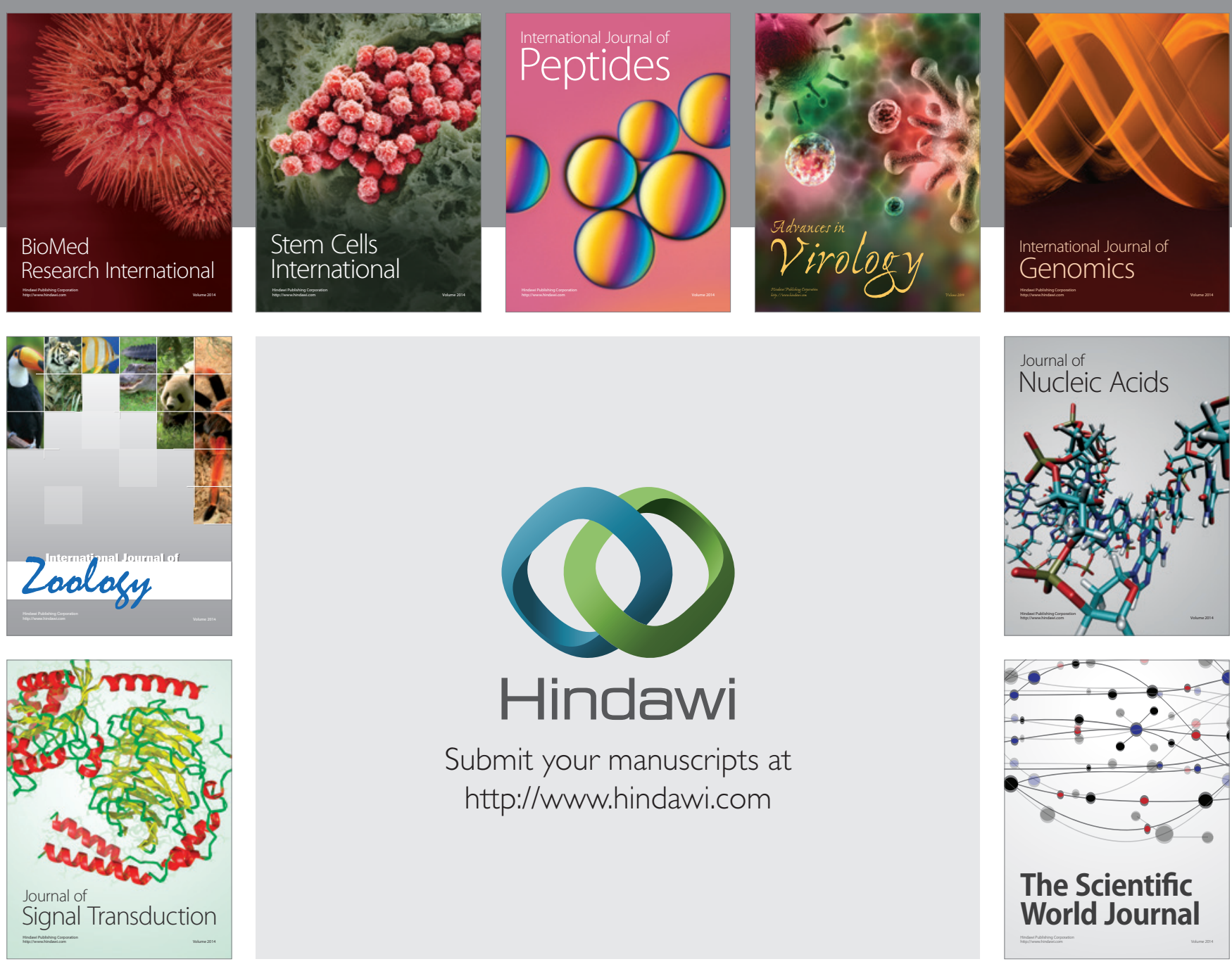

Submit your manuscripts at

http://www.hindawi.com
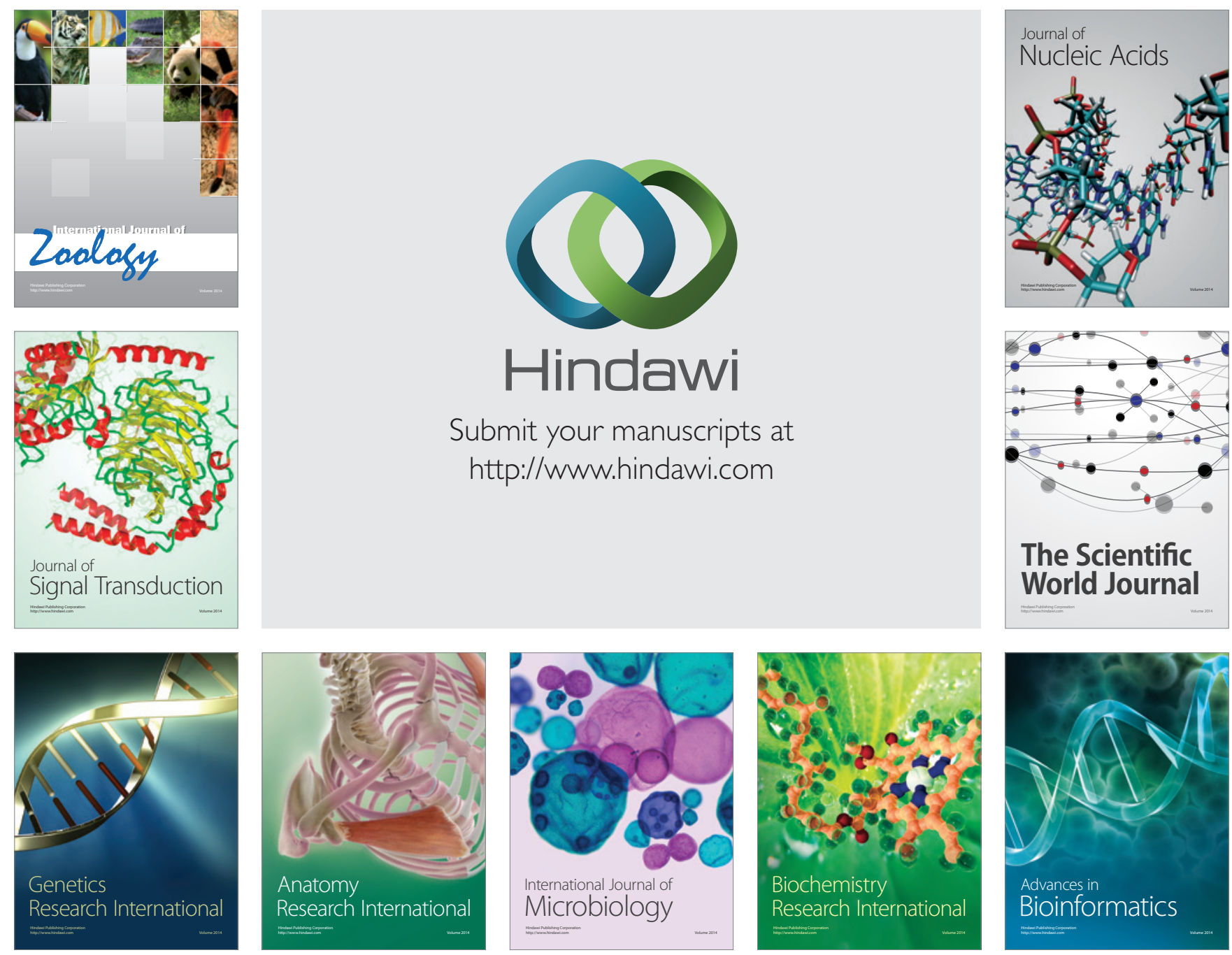

The Scientific World Journal
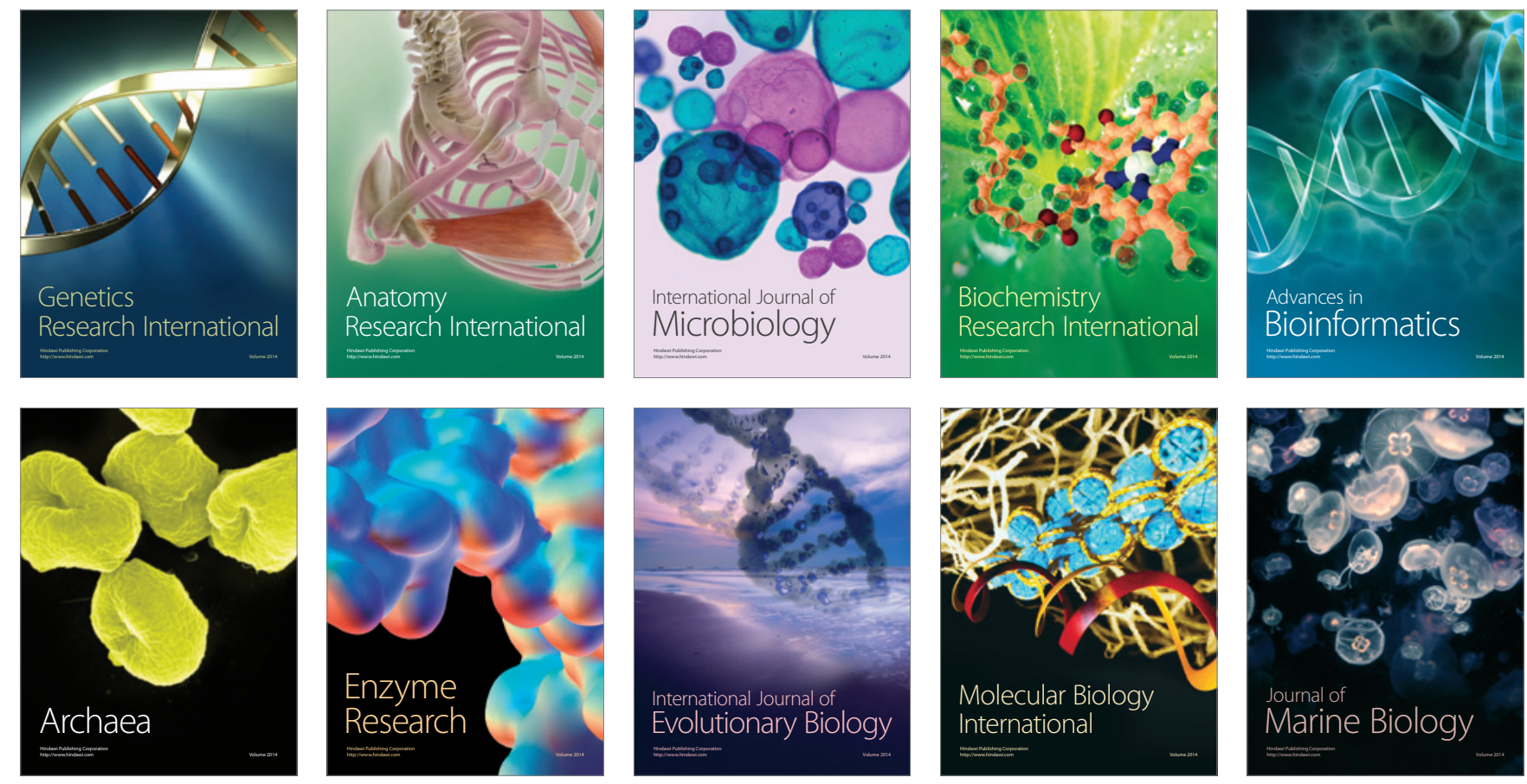